\title{
Comparative evaluation of salivary malondialdehyde levels as a marker of lipid peroxidation in early childhood caries
}

\author{
Divya Subramanyam ${ }^{1}$, Deepa Gurunathan ${ }^{1}$, R. Gaayathri $^{2}$, V. Vishnu Priya ${ }^{2}$
}

Correspondence: Dr. Divya Subramanyam

Email: smiley.divya24@gmail.com
'Department of Pediatric and Preventive Dentistry, Saveetha Dental College, Chennai, Tamil Nadu, India, ${ }^{2}$ Department of Biochemistry, Saveetha Dental College, Chennai, Tamil Nadu, India

\section{ABSTRACT}

Objective: The aim of this study was to evaluate the association between lipid peroxidation and dental caries in children with ECC by estimating the levels of MDA in saliva of children. Materials and Methods: A total of 150 children were selected; 75 children with ECC and 75 children without caries (non-ECC). Saliva samples were collected and centrifuged at $12,000 \mathrm{rpm}$ for $24 \mathrm{~min}$ at $4^{\circ} \mathrm{C}$ to obtain a supernatant. MDA levels were estimated by Buege and Aust method by using thiobarbituric acid. The data obtained were analyzed by Student's $t$-test to compare MDA levels between the groups. Results: MDA levels were higher in children with ECC. There was no statistically significant difference between children with ECC and without ECC (non-ECC). Conclusion: MDA levels were slightly higher in children with ECC, indicating the role of lipid peroxidation in the carious process.

Key words: Dental caries, free radicals, salivary biomarker

\section{INTRODUCTION}

Dental caries is a complex process of demineralization and dissolution of substance of the teeth leading to cavitation. ${ }^{[1]}$ It has been shown to have a multifactorial etiology which leads to the initiation and progression of the lesion. ${ }^{[2]}$ According to the American Academy of Pediatric Dentistry, early childhood caries (ECC) is defined as the presence of one or more decayed (noncavitated or cavitated), missing (due to caries), or filled tooth (DMFT) surfaces in any primary tooth in a child 71 months of age or younger. ${ }^{[3]}$ Saliva plays a very important role in maintenance of oral health and also against dental caries as a first line of defense. ${ }^{[4]}$ It mediates the oral health of individuals

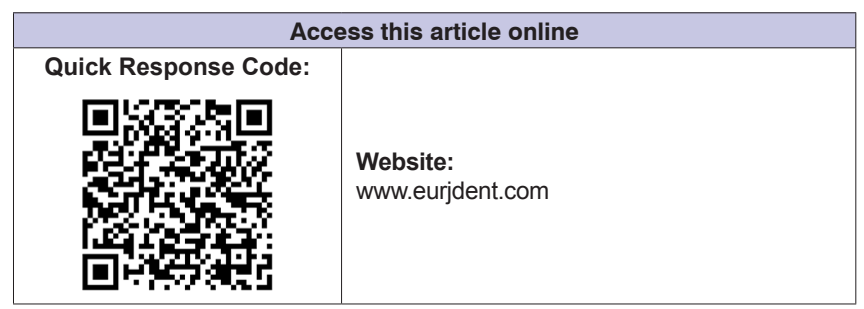

through various defense mechanisms such as its flow, buffering capacity, lipids, total protein, and its antioxidant system. ${ }^{[4]}$ It is widely used as a biomarker for evaluating the oxidative damage mediated by free radicals including lipid peroxidation occurring in the oral cavity. ${ }^{[5]}$ The imbalance between the free radicals and antioxidants leads to lipid or protein damage. ${ }^{[6]}$ It has been shown that the biomarkers for the detection of free radicals are seen in saliva of children and adolescents. ${ }^{[7]}$ Initiation and progression of dental caries is modified by immunological defense mechanism present in saliva. ${ }^{[8]}$ It is shown in the

This is an open access article distributed under the terms of the Creative Commons Attribution-NonCommercial-ShareAlike 3.0 License, which allows others to remix, tweak, and build upon the work non-commercially, as long as the author is credited and the new creations are licensed under the identical terms.

For reprints contact: reprints@medknow.com

How to cite this article: Subramanyam D, Gurunathan D, Gaayathri R, Vishnu Priya V. Comparative evaluation of salivary malondialdehyde levels as a marker of lipid peroxidation in early childhood caries. Eur $\mathrm{J}$ Dent 2018;12:67-70.

DOI: 10.4103/ejd.ejd_266_17 
literature that lipid peroxidation reaction releasing the free radicals has been associated with the pathogenesis of several pathological disorders. ${ }^{[9]}$ Lipid peroxidation is known to cause alterations in the structure and function of the host cells by producing malondialdehyde (MDA) as the by-product. ${ }^{[10,11]}$ Lipid peroxidation and cell damage in the host tissue affect the immune mechanism in saliva, leading to initiation and progression of bacterial infections such as dental caries. $^{[12]}$ Reactive free radicals have the capacity to modify the reactions occurring in the cells and cause deterioration of lipids, proteins, and nucleotides present in the tissue. ${ }^{[11]}$ Saliva has a role in controlling the pathogenesis of plaque formation leading to reduced susceptibility of dental caries by production of certain chemical reactions. ${ }^{[13]}$ The goal of antioxidants is to prevent the free radical-mediated oxidative damage to the host cell membrane. ${ }^{[14]}$ The most widely used diagnostic assay for evaluation of lipid peroxidation reaction is by measuring the concentrations of MDA using thiobarbituric acid (TBARS). ${ }^{[15]}$ MDA is one of the principal end products of lipid peroxidation, which is used as a biomarker of cell membrane injury. ${ }^{[16]}$ It is hypothesized that MDA levels increase in children with caries. Previously, studies have been conducted evaluating the association between MDA levels and dental caries in adult population. ${ }^{[17]}$

However, there is a lacuna of research regarding the effect of lipid peroxidation in the initiation and progression of ECC in children using TBARS assay. Hence, this study aimed to evaluate the levels of MDA in saliva to find the association between lipid peroxidation and ECC.

\section{MATERIALS AND METHODS}

Ethical approval and clearance for this in vitro study was obtained from the Institutional Review Board, Saveetha Dental College, Ref no: SRB/STPG15/41. Children within the age group of 6 years and free from any systemic diseases, who reported to the Department of Pediatric and Preventive Dentistry were examined and included in the study. A total of 150 children were selected: 75 children with ECC and 75 children without ECC (non-ECC). Informed consent according to the World Medical Declaration of Helsinki was obtained from the parents/guardians. Children who were under antibiotic therapy over a period of 2 weeks and with any systemic conditions were excluded from the study. Sample size was calculated with a power of 0.95 from a previous study ${ }^{[17]}$ and arrived to a total sample of 150 using G Power version 3.1.
(Allegemeine Psychologie und Arbeitspsychologie, Heinrich-Heine-Universität, Düsseldorf)

\section{Sample collection and analysis}

Five milliliters of unstimulated saliva was obtained from all the children by spit method in a sterile test tube following standard precollection protocol. ${ }^{[18]}$ Saliva was centrifuged at $12,000 \mathrm{rpm}$ for $24 \mathrm{~min}$ at $4^{\circ} \mathrm{C}$ to obtain a supernatant. The MDA content of the saliva was evaluated by Buege and Aust method by using TBA. ${ }^{[19]}$ The MDA obtained from lipid peroxidation reaction reacts with TBA to yield a yellow fluorescent product. The absorbance of $2 \mathrm{ml}$ colored layer was measured by using a spectrophotometer at $335 \mathrm{~nm}$.

\section{Statistical analysis}

The data obtained were subjected to a statistical analysis using Student's $t$-test by using SPSS version 21 (SPSS Inc., Chicago, IL, USA) with $P=0.05$ [Table 1].

\section{RESULTS}

The mean age of the participants in both the groups was 5.46 years. The MDA levels were relatively higher in children with ECC $(0.26 \pm 0.24)$ compared to that of non-ECC group $(0.17 \pm 0.14)$ but were not statistically significant $(P>0.05)$ [Table 1$]$.

\section{DISCUSSION}

ECC commonly affects preschoolers and can progress more in those who are at a high risk. It can cause a great impact on the quality of life of young children. ECC is a multifactorial disease. ${ }^{[20]}$ Host factors such as saliva play an important role in maintaining the oral health of the individual. Various biomarkers of lipid peroxidation are seen in saliva. Lipid peroxidation is initiated due to oxidative stress, which seems to be produced due to local oral factors such as oral hygiene status. ${ }^{[7]}$ Lipid peroxidation leads to oxidative degradation of lipids. The alteration of the structural integrity of the host cell membrane in oral cavity causes peroxidation of lipids, resulting in a diseased condition. ${ }^{[21]}$ Alteration of free radicals,

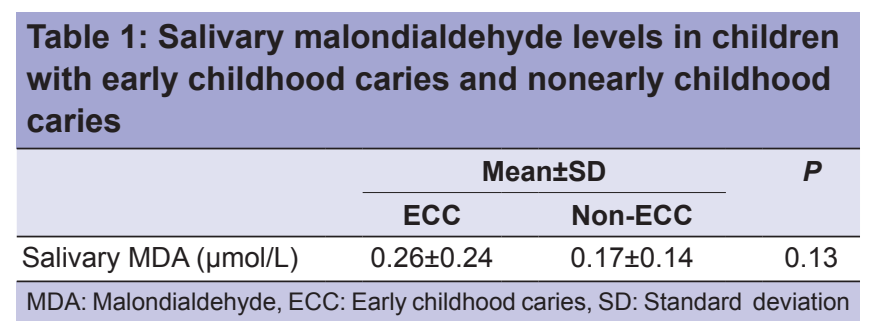


reactive oxygen species (ROS), and antioxidants initiates and leads to progression of dental caries. ${ }^{[22]}$ ROS reacts with polyunsaturated fatty acids to release free radicals. ${ }^{[23]}$ The cellular damage caused by free radicals leads to peroxidation of lipids producing MDA, thereby causing oxidative stress. ${ }^{[23,24]}$ ECC is a multifactorial inflammatory disease because bacterial toxins activate the matrix metalloproteinase such as collagenase, which causes breakdown of collagen matrix in the dentin and initiates host immune response leading to dentinal caries. ${ }^{[7,25]}$ Inflammatory process initiates lipid peroxidation reaction that leads to the production of MDA which in turn alters the immunological mediators such as salivary peroxidase system and modifies the bacterial metabolism leading to dental caries. ${ }^{[7]}$ In this study, saliva is used as a diagnostic tool since it is easy to collect and there is an enhanced positive correlation between salivary parameters and oral diseases. ${ }^{[26]}$ Antioxidants are necessary to hinder the oxidation reaction produced in the oral cavity, thereby reducing the free radicals. ${ }^{[10]}$ Insufficient levels of antioxidants or inhibition of antioxidant enzymes causes oxidative stress, which in turn causes host cell damage. ${ }^{[27]}$ Oral fluids and cells have some antioxidant processes which halt the release of ROS and free radicals for prevention of oral disease such as ECC. ${ }^{[28]}$

It has been shown that oxidant-antioxidant imbalance mediated by oxidative stress causes various oral diseases. ${ }^{[7]}$ Oxidative stress occurs due to alteration in the physical and mental activities which causes decrease in the antioxidant defense mechanism, which in turn initiates lipid peroxidation reaction. ${ }^{[29]}$ It is caused either by overproduction of free radicals mediated by inflammation or due to alteration in antioxidant status. ${ }^{[7]} \mathrm{MDA}$ is one of the major by-products of lipid peroxidation, which is produced in the host tissue cells in the saliva, leading to decreased host immune response. ${ }^{[28]}$ Compromised immune response impairs the protective action of saliva, which in turn prevents the control of bacteria that form dental plaque leading to ECC. ${ }^{[7]}$ Many studies have evaluated total antioxidant capacity (TAC) levels in dental caries. ${ }^{[7,26-32]}$ The study by Hegde et al. showed that TAC increased in children with rampant caries. ${ }^{[2]}$ There are only few studies which evaluated the MDA levels in saliva and its association with dental caries. ${ }^{[17,24]}$ There is a lack of sufficient evidence regarding the association of MDA levels as a biomarker for lipid peroxidation in saliva and ECC. Hence, this study aimed to direct the influence of lipid peroxidation on ECC.
The present study evaluated the levels of MDA in children with ECC. The salivary MDA concentration in saliva was found to be comparatively higher in ECC group than that of the control group, but there was no significant difference between them, indicating some role of lipid degradation in the pathogenesis of dental caries. Sarode et al., who evaluated the MDA levels in higher age group, reported that there was a significant association between MDA levels among dental caries and control groups. ${ }^{[17]}$ Rai et al. studied the relation between lipid peroxidation and dental caries and found that there was no difference in salivary MDA levels in children with or without ECC. ${ }^{[21]}$ Findings of a study performed by Uberos et al. reported that TAC of saliva was higher in primary teeth of children with dental caries. ${ }^{\left[{ }^{[0]}\right.}$ Oztürk et al. compared the association between DMFT and salivary MDA levels in the dental caries, but they did not find any significant difference in salivary MDA levels among the groups studied. ${ }^{[31]}$ Since ECC is a common hurdle faced by dentists, there is a paradigm shift over the recent years where the current scenario is to prevent the dental caries by identifying the risk factors early to reduce the initiation of the disease process. Although it is a time-consuming and complicated process, the evaluation of MDA as a risk factor for ECC may be essential to diagnose and perform the treatment at the earliest. Antioxidants can be prescribed, which are capable of neutralizing the free radicals induced by oxidative stress, thereby preventing lipid peroxidation process which minimizes the bacterial infection. ${ }^{[10,30]}$ The study did not assess the correlation between oral hygiene levels and MDA levels in children with ECC, which is the limitation of the study. Further clinical studies are required to find the association between MDA and other salivary biomarkers, to analyze the dietary practices and to determine the distinctive role of lipid peroxidation in ECC. And also, future researches should be conducted to determine the role of antioxidants such as Vitamin C and Vitamin E in reducing the oxidative stress-induced lipid peroxidation.

\section{CONCLUSION}

The MDA levels were relatively greater in children with ECC, thereby indicating the association of lipid peroxidation with dental caries process. However, there was no significant difference to determine a definite positive relation between lipid peroxidation and ECC. 


\section{Acknowledgment}

The authors would like to thank the Department of Biochemistry for the support and guidance.

\section{Financial support and sponsorship Nil.}

\section{Conflicts of interest}

There are no conflicts of interest.

\section{REFERENCES}

1. Balsaraf S, Chole RH. Epidemiology of dental caries - A review. Univ Res J Dent 2016;6:206-12.

2. Colak H, Dulgergil CT, Dalli M, Hamidi MM. Early childhood caries update: A review of causes, diagnoses, and treatments. J Nat Sci Biol Med 2013;4:29-38.

3. Drury TF, Horowitz AM, Ismail AI, Maertens MP, Rozier RG, Selwitz RH, et al. Diagnosing and reporting early childhood caries for research purposes. A Report of a Workshop Sponsored by the National Institute of Dental and Craniofacial Research, the Health Resources and Services Administration, and the Health Care Financing Administration. J Public Health Dent 1999;59:192-7.

4. Gabryel-Porowska H, Gornowicz A, Bielawska A, Wójcicka A, Maciorkowska E, Grabowska SZ, et al. Mucin levels in saliva of adolescents with dental caries. Med Sci Monit 2014;20:72-7.

5. Pandey P, Reddy NV, Rao VA, Saxena A, Chaudhary CP. Estimation of salivary flow rate, $\mathrm{pH}$, buffer capacity, calcium, total protein content and total antioxidant capacity in relation to dental caries severity, age and gender. Contemp Clin Dent 2015;6:S65-71.

6. Pham-Huy LA, He H, Pham-Huy C. Free radicals, antioxidants in disease and health. Int J Biomed Sci 2008;4:89-96.

7. Tóthová L, Kamodyová N, Červenka T, Celec P. Salivary markers of oxidative stress in oral diseases. Front Cell Infect Microbiol 2015:5:73.

8. Shivakumar KM, Vidya SK, Chandu GN. Dental caries vaccine. Indian J Dent Res 2009;20:99-106.

9. Barrera G. Oxidative stress and lipid peroxidation products in cancer progression and therapy. ISRN Oncol 2012;2012:137289.

10. Lobo V, Patil A, Phatak A, Chandra N. Free radicals, antioxidants and functional foods: Impact on human health. Pharmacogn Rev 2010;4:118-26.

11. Marcotte H, Lavoie MC. Oral microbial ecology and the role of salivary immunoglobulin A. Microbiol Mol Biol Rev 1998;62:71-109.

12. Almerich- Silla JM, Montiel-Company JM, Pastor S, Serrano F, Puig-Silla M, Dasi F. Oxidative stress parameters in saliva and its association with periodontal disease and types of bacteria. Dis Markers. 2015; 2015: 653537.

13. Rahman K. Studies on free radicals, antioxidants, and co-factors. Clin Interv Aging 2007;2:219-36.

14. Frijhoff J, Winyard PG, Zarkovic N, Davies SS, Stocker R, Cheng D, et al. Clinical relevance of biomarkers of oxidative stress. Antioxid
Redox Signal 2015;23:1144-70.

15. Ayala A, Muñoz MF, Argüelles S. Lipid peroxidation: Production, metabolism, and signaling mechanisms of malondialdehyde and 4-hydroxy-2-nonenal. Oxid Med Cell Longev 2014;2014:360438.

16. Grotto D, Maria LS, Valentini J, Paniz C, Schmitt G, Garcia SC, et al. Importance of the lipid peroxidation biomarkers and methodological aspects for malondialdehyde quantification. Quimica Nova 2009;32:169-74

17. Sarode G, Shelar A, Sarode S, Bagul N. Association between dental caries and lipid peroxidation in saliva. Int J Oral Maxillofac Pathol 2012;3:2-4.

18. Henson BS, Wong DT. Collection, storage, and processing of saliva samples for downstream molecular applications. Methods Mol Biol 2010;666:21-30

19. Buege JA, Aust SD. Microsomal lipid peroxidation. Methods Enzymol 1978;52:302-10.

20. Prakash P, Subramaniam P, Durgesh BH, Konde S. Prevalence of early childhood caries and associated risk factors in preschool children of urban Bangalore, India: A cross-sectional study. Eur J Dent 2012;6:141-52.

21. Rai B, Kharb S, Jain R, Anand SC. Salivary LPO product malondialdehyde in various dental diseases. World J Med Sci 2006;1:100-1.

22. Battino M, Ferreior MS, Gallardo I, Newman HN, Bullon P. The antioxidant capacity of saliva. J Clin Periodontol 2002;29:189-94.

23. Canakci CF, Cicek Y, Yildirim A, Sezer U, Canakci V. Increased levels of 8-hydroxydeoxyguanosine and malondialdehyde and its relationship with antioxidant enzymes in saliva of periodontitis patients. Eur J Dent 2009;3:100-6.

24. Hegde AM, Raj K, Shetty S. Relation of caries status on the salivary total antioxidant levels in asthmatic children. Contemp Clin Dent 2012;3:402-5.

25. Southward K. The systemic theory of dental caries. Gen Dent 2011:59:367-73.

26. Martí-Álamo S, Mancheño-Franch A, Marzal-Gamarra C, Carlos-Fabuel L. Saliva as a diagnostic fluid. Literature review. J Clin Exp Dent 2012;4:e237-43.

27. Birben E, Sahiner UM, Sackesen C, Erzurum S, Kalayci O. Oxidative stress and antioxidant defense. World Allergy Organ J 2012;5:9-19.

28. Ahmadi-Motamayel F, Goodarzi MT, Hendi SS, Kasraei S, Moghimbeigi A. Total antioxidant capacity of saliva and dental caries. Med Oral Patol Oral Cir Bucal 2013;18:e553-6.

29. Atsumi T, Tonosaki K, Fujisawa S. Salivary free radical-scavenging activity is affected by physical and mental activities. Oral Dis 2008;14:490-6.

30. Uberos J, Alarcón JA, Peñalver MA, Molina-Carballo A, Ruiz M, González $\mathrm{E}$, et al. Influence of the antioxidant content of saliva on dental caries in an at-risk community. Br Dent J 2008;205:E5.

31. Oztürk LK, Furuncuoğlu H, Atala MH, Uluköylü O, Akyüz S, Yarat A, et al. Association between dental-oral health in young adults and salivary glutathione, lipid peroxidation and sialic acid levels and carbonic anhydrase activity. Braz J Med Biol Res 2008;41:956-9.

32. Lü JM, Lin PH, Yao Q, Chen C. Chemical and molecular mechanisms of antioxidants: Experimental approaches and model systems. J Cell Mol Med 2010;14:840-60 